Research Article

\title{
Factors Influencing Nonrenewal of Health Insurance Membership in Ejisu-Juaben Municipality of Ashanti Region, Ghana
}

\author{
Kwawukume Mawumenyo Aku, ${ }^{1}$ Kofi Akohene Mensah, ${ }^{1}$ Peter Twum (D), \\ Peter Agyei-Baffour, ${ }^{1}$ Daniel Opoku, ${ }^{1}$ and Joseph Kwasi Brenyah ${ }^{2}$ \\ ${ }^{1}$ Department of Health Policy, Management and Economics, School of Public Health, \\ Kwame Nkrumah University of Science and Technology, Kumasi, Ghana \\ ${ }^{2}$ Department of Global and International Health, School of Public Health, \\ Kwame Nkrumah University of Science and Technology, Kumasi, Ghana
}

Correspondence should be addressed to Peter Twum; twumpeter2000@yahoo.com

Received 24 February 2021; Revised 5 June 2021; Accepted 28 June 2021; Published 10 July 2021

Academic Editor: Hamidreza Karimi-Sari

Copyright (C) 2021 Kwawukume Mawumenyo Aku et al. This is an open access article distributed under the Creative Commons Attribution License, which permits unrestricted use, distribution, and reproduction in any medium, provided the original work is properly cited.

\begin{abstract}
Background. In the quest to prevent households from making catastrophic expenditures at the point of seeking healthcare, the government of Ghana introduced the National Health Insurance in 2003. However, people are reluctant to renew their membership. This study was, therefore, conducted to identify factors influencing the nonrenewal of National Health Insurance membership in the Ejisu-Juaben Municipality. Methods. A cross-sectional study was conducted among 427 respondents in the Ejisu-Juaben Municipality to ascertain factors influencing the nonrenewal of health insurance membership status. Data were entered and analyzed using Stata version 14. Univariate and multivariate analyses were performed to determine sociodemographic factors, household factors, and systemic factors influencing the nonrenewal of health insurance status. Statistical significance for all testing was set as $p \leq 0.05$. Results. Sociodemographic factors such as gender $(\mathrm{AOR}=0.531 ; \mathrm{CI}=0.287-0.985)$ and educational level $(\mathrm{AOR}=5.268 ; \mathrm{CI}=1.130-24.551))$ were associated with the nonrenewal of health insurance membership. Income levels in Ghana Cedis were 500-1000 (AOR $=0.216 ; \mathrm{CI}=0.075-0.617)$ and $1001-2000(\mathrm{AOR}=0.085 ; \mathrm{CI}=0.019-0.383)$. Systemic decision on factors such as clients' satisfaction $(\mathrm{AOR}=0.149 ; \mathrm{CI}=0.035-0.640)$, making copayment $(\mathrm{AOR}=0.152$; $\mathrm{CI}=0,068-0.344)$, acquiring all prescribed drugs $(\mathrm{AOR}=4.191 ; \mathrm{CI}=2.027-8.668)$, and awareness of mobile renewal $(\mathrm{AOR}=3.139 ; \mathrm{CI}=1.462-6.739)$ was associated with nonrenewal of membership. Conclusions. The nonrenewal of health insurance membership was influenced by sociodemographic, household, and systemic factors. Therefore, the Municipal Health Directorate and the National Health Insurance Authority have to work on these factors to reach the target of $100 \%$ active coverage in the municipality.
\end{abstract}

\section{Background}

Health insurance coverage is an imperative aspect of achieving Universal Health Coverage (UHC) $[1,2]$. In Canada, every citizen and legal residents of the country have basic health insurance coverage which is provided by the government [3]. The public programme, therefore, account for only $37.1 \%$ of residents. This shows that public-funded health insurance as practiced by Canada is the way to go to ensure equity and financial protection.

Learning from the developed countries, some low- and middle-income countries have begun introducing health insurance to their populations. A study by Escobar et al (2010) in Costa Rica, Peru, Indonesia, Rural China, Columbia as well as Ghana on the impact of health insurance in low- and middle-income countries ascertained a positive 
correlation between health insurance status and good health outcomes $[4,5]$.

In 2012, the Ghana Parliament made the membership of National Health Insurance Scheme (NHIS) mandatory for all residents in the country through an Act of Parliament [6]. However, out of the 18.5 million people who are registered into the scheme, only 10 million $(40 \%)$ are active $[7,8]$. This, if not addressed, could hamper the country's effort to attain $100 \%$ health insurance coverage for the Ghanaian population by the year 2030 .

This calls for pragmatic measures in retaining the existing members in addition to enrolling the noninsured in order not to deter Ghana's effort to achieve UHC. Some studies have been conducted in the Eastern, Central, and Volta Regions of Ghana to ascertain factors that influence enrolment and retention into the health insurance scheme $[9,10]$. However, Ashanti Region, the second largest and the most populated region in Ghana, had not benefited from such studies. In addition, for those regions, which have benefited from such studies, the investigations were facilitybased, scheme-based, and based on individual factors influencing the nonrenewability of NHIS. How sociodemographic factors, household factors, and health system factors influenced the nonrenewability of NHIS membership had not been adequately explored in Ghana. Therefore, there was a need for such a study to be conducted in the EjisuJuaben Municipality as a lesson from the region could be used in other regions in the country and even in other countries in the subregion. This will help put measures in place to propel the country toward achieving its aim of $100 \%$ health insurance coverage.

\section{Methods}

2.1. Design. A cross-sectional study was conducted from 1 June 2019 to 31 December 2019 among 427 people in EjisuJuaben Municipality who have ever registered with NHIS to find out the factors that influence the nonrenewal of health insurance membership.

2.2. Sampling Method. Multistage sampling, involving cluster and simple random sampling methods, was used in this study. Ejisu-Juaben Municipality has five submunicipal health administrative areas. Each health administration was taken as a cluster. One community was selected from each cluster using a simple random sampling method. Here, the names of the communities in each submunicipality were written on pieces of a paper and put into a box and thoroughly shaken. One community was selected in each submunicipality resulting in a total of five communities sampled for the study. In each of these selected communities, 85 household heads were interviewed except in Ejisu, the capital town where 87 were interviewed.

In reaching each of the selected communities, the researcher stood at the center and span a pen. Houses the tip of the pen pointed at were chosen and the household heads were engaged once they were qualified to take part in the study. On leaving each house, the opposite houses were selected and household heads who met the inclusion criteria were interviewed. In a house where there was no opposite house, the researcher span the pen again and repeated the same procedure to engage household heads. These processes were replicated across all selected communities till the required sample size for each community was attained.

2.3. Sample Size. Since the number of households in the Ejisu-Juaben Municipality from the 2010 census is 33,078, which is a relatively large population, the sample size was calculated using Cochran's formula:

$$
\mathrm{No}=\frac{Z^{2} p q}{e^{2}}
$$

where No is the sample size, $p$ is the assumed prevalence of renewal of NHIS membership in the Ejisu-Juaben district, $q$ is (1- $p), Z$ is the significance level at $95 \%$ confidence interval read from the $z$ table to be 1.96 , and $e$ is the margin of error, which is assumed to be $5 \%$.

For this sample calculation, a $50 \%$ prevalence rate of renewal was assumed. Therefore, our sample size was calculated as

$$
\mathrm{No}=\frac{1.96^{2}(0.5)(0.5)}{0.05^{2}}=384 .
$$

Adjusting for a nonresponse rate of $10 \%$, the final sample size was

$$
\begin{aligned}
& \text { final sample size }=\frac{\text { effective sample size }}{(1-\text { nonresponse rate anticipated })}, \\
& \text { final sample size }=\frac{384}{(1-0.1)}=427 \text { households heads. }
\end{aligned}
$$

2.4. Data Collection Techniques and Tools. Data were collected using a semistructured questionnaire designed on the Kobo Collect application. Kobo Collect is Kobo Toolbox's data collection application that is used to collect survey data and can be used on any android phone. The questionnaires were administered by four trained research assistants who communicated in English and Twi (the local language of study participants).

Data on sociodemographic characteristics, such as age, educational level, ethnicity, marital status, occupation, religion, place of residence, and income, were collected. Data collected on the household level comprised of household income, the health status of a household, household size, the number of dependents in a household, the presence of a person with chronic disease in the household, and the wealth status of a household. Systematic factors assessed include distance to a health facility, road network, quality of care, copayments, and availability of medicines.

2.5. Data Handling and Analysis. Data were exported from the Kobo Collect application into Microsoft Excel for coding and further imported into Stata version 14.1 for analysis. 
Data validation was done to ensure data quality. Descriptive data were presented using frequencies and percentages. Univariate and multivariate analyses were performed to establish associations between sociodemographic factors, household factors, and systematic factors influencing the nonrenewal of NHIS membership. Statistical significance for all testing was set as $p \leq 0.05$.

\section{Results}

3.1. Background Characteristics of Respondents. The mean age of the respondents was $36.3 \pm 0.51$ years, and a little over half $(57.79 \%)$ were females. Those who completed Junior High School were $30.48 \%$ and traders constituted $26.14 \%$. Vast majority (82.25\%) of the respondents were Akan and Christians constituted $89.93 \%$ while $70.26 \%$ lived in urban areas as shown in Table 1.

3.2. Sociodemographic Factors Influencing the Nonrenewal of Health Insurance Membership. In univariate and multivariate regression analyses in Table 2, sociodemographic factors such as gender and level of education influenced a person's decisions not to renew their health insurance membership. Females were 0.531 less likely not to renew their health insurance membership compared to males $(\mathrm{AOR}=0.531$; $95 \% \mathrm{CI}=0.287-0.985$ ). In addition, people with MSLC, as their highest level of education, were five times more likely not to renew their NHIS membership as compared to those with other levels of education $(\mathrm{AOR}=5.268 ; 95 \%$ $\mathrm{CI}=1.130-24.551)$.

3.3. Logistics Regression of Household Factors That Influence the Nonrenewal of Health Insurance Membership. In univariate and multivariate analyses, as shown in Table 3, household factors such as household income and household expenditure influenced a person's decision not to renew their health insurance membership. For instance, those with an average household income of GH\$500-1000 were 0.216 times less likely not to renew compared to those who earn less than $\mathrm{GH} \$ 500(\mathrm{AOR}=0.216 ; 95 \% \mathrm{CI}=0.075-0.675)$ and those earning GH\$1001-2000 were 0.085 times less likely not to renew compared to those who earn less than $\mathrm{GH} \$ 500$ $(\mathrm{AOR}=0.085 ; 95 \% \mathrm{CI}=0.019-0.389)$.

3.4. Systematic Factors Influencing the Nonrenewal of Health Insurance Membership. Table 4 shows that the majority of the respondents $(60.67 \%)$ lived $1-5 \mathrm{~km}$ away from a health facility, $83.45 \%$ had good road network to the health facility, $85.85 \%$ had a good experience on their last hospital visit, and $65.47 \%$ made some form of copayment though they were insured. The majority of the respondents $(65.47 \%)$ were aware of the use of mobile phones to renew their national health insurance cards, but $75.06 \%$ of those aware did not know the code used to renew their membership.

A little over half of the respondents (50.84\%) lived $1-5 \mathrm{~km}$ from the health insurance office, with $6.24 \%$ living less than $1 \mathrm{~km}, 37.65 \%$ lived $6-10 \mathrm{~km}$ away from the health
TABLE 1: Background characteristics of the respondents.

\begin{tabular}{|c|c|c|}
\hline Characteristic & Frequency $(n=417)$ & Percentage \\
\hline Age $($ mean \pm SD $)$ & \multicolumn{2}{|c|}{$36.3 \pm 0.51$} \\
\hline \multicolumn{3}{|l|}{ Age } \\
\hline $18-27$ & 76 & 18.23 \\
\hline $28-37$ & 191 & 45.80 \\
\hline $38-47$ & 90 & 21.58 \\
\hline $48-57$ & 39 & 9.35 \\
\hline$>58$ & 21 & 5.04 \\
\hline \multicolumn{3}{|l|}{ Gender } \\
\hline Male & 176 & 42.21 \\
\hline Female & 241 & 57.79 \\
\hline \multicolumn{3}{|l|}{ Level of education } \\
\hline None & 41 & 9.83 \\
\hline Primary & 53 & 12.71 \\
\hline JHS & 127 & 30.46 \\
\hline SHS & 90 & 21.58 \\
\hline Tertiary & 87 & 20.86 \\
\hline MSLC & 19 & 4.56 \\
\hline \multicolumn{3}{|l|}{ Ethnicity } \\
\hline Akan & 343 & 82.25 \\
\hline Ewe & 13 & 3.12 \\
\hline Northern ethnic groups & 36 & 8.63 \\
\hline $\mathrm{Ga}$ & 6 & 1.44 \\
\hline Others & 19 & 4.56 \\
\hline \multicolumn{3}{|l|}{ Marital status } \\
\hline Single & 96 & 23.02 \\
\hline Married & 239 & 57.31 \\
\hline Divorced & 36 & 8.63 \\
\hline Widowed & 23 & 5.52 \\
\hline Cohabiting & 15 & 3.60 \\
\hline Separated & 8 & 1.92 \\
\hline \multicolumn{3}{|l|}{ Employment } \\
\hline Employed & 370 & 88.73 \\
\hline Unemployed & 47 & 11.27 \\
\hline \multicolumn{3}{|l|}{ Occupation } \\
\hline None & 17 & 4.08 \\
\hline Trading & 109 & 26.14 \\
\hline Farming & 69 & 16.55 \\
\hline Civil/public servant & 76 & 18.23 \\
\hline Hairdresser & 19 & 4.56 \\
\hline Seamstress & 15 & 3.60 \\
\hline Businessperson & 20 & 4.80 \\
\hline Others & 92 & 22.06 \\
\hline \multicolumn{3}{|l|}{ Place of residence } \\
\hline Rural & 124 & 29.74 \\
\hline Urban & 293 & 70.26 \\
\hline \multicolumn{3}{|l|}{ Religion } \\
\hline Christianity & 375 & 89.93 \\
\hline Islam & 41 & 9.83 \\
\hline Traditional & 1 & 0.24 \\
\hline
\end{tabular}

insurance office, and 5.28\% lived more than $10 \mathrm{~km}$ away from the health insurance office.

Only $49.40 \%$ of the respondents received all the drugs prescribed while $50.60 \%$ not received all the prescribed drugs.

3.5. Logistic Regression Analysis of Systemic Factors Influencing Health Insurance Renewal. The univariate and multivariate logistic regression analyses in Table 5 show that the 
TABLE 2: Sociodemographic factors influencing the nonrenewal of health insurance membership.

\begin{tabular}{|c|c|c|c|c|c|c|}
\hline \multirow[b]{2}{*}{ Characteristic } & \multicolumn{3}{|c|}{ Univariate logistic regression } & \multicolumn{3}{|c|}{ Multivariate logistic regression } \\
\hline & $\begin{array}{l}\text { Odds ratio } \\
\text { (OR) }\end{array}$ & $\begin{array}{l}\text { 95\% confidence } \\
\text { interval }\end{array}$ & $P$ value & $\begin{array}{c}\text { Adjusted odds ratio } \\
\text { (AOR) }\end{array}$ & $\begin{array}{c}\text { 95\% confidence } \\
\text { interval }\end{array}$ & $P$ value \\
\hline Age & & & 0.90 & & & 0.34 \\
\hline $18-27$ & Ref & & & Ref & & \\
\hline $28-37$ & 0.912 & $0.465-1.789$ & 0.79 & 1.387 & $0.585-3.287$ & 0.46 \\
\hline $38-47$ & 1.237 & $0.587-2.611$ & 0.58 & 1.733 & $0.606-4.958$ & 0.31 \\
\hline $48-57$ & 0.889 & $0.329-2.403$ & 0.82 & 0.743 & $0.199-2.768$ & 0.67 \\
\hline$>58$ & 0.957 & $0.281-3.263$ & 0.94 & 0.621 & $0.120-3.231$ & 0.57 \\
\hline Gender & Ref & & 0.01 & Ref & & \\
\hline Male & - & - & - & - & - & - \\
\hline Female & 0.496 & $0.304-0.808$ & 0.01 & 0.531 & $0.287-0.985$ & 0.04 \\
\hline Level of education & & & 0.32 & & & \\
\hline None & Ref & & & Ref & & \\
\hline Primary & 2.340 & $0.759-0.721$ & 0.14 & 2.388 & $0.704-8.104$ & 0.16 \\
\hline JHS & 1.678 & $0.596-4.725$ & 0.33 & 1.349 & $0.435-4.187$ & 0.61 \\
\hline SHS & 1.800 & $0.618-5.240$ & 0.28 & 1.571 & $0.483-5.117$ & 0.45 \\
\hline Tertiary & 1.500 & $0.505-4.453$ & 0.47 & 1.837 & $0.483-6.993$ & 0.37 \\
\hline MSLC & 4.200 & $1.121-15.731$ & 0.03 & 5.268 & $1.130-24.551$ & 0.03 \\
\hline Ethnicity & & & 0.76 & & & \\
\hline Akan & Ref & & & Ref & & \\
\hline $\begin{array}{l}\text { Northern ethnic } \\
\text { groups }\end{array}$ & 0.766 & $0.307-1.912$ & 0.57 & 0.971 & $0.322-2.928$ & 0.96 \\
\hline $\mathrm{Ga}$ & 1.915 & $0.344-10.669$ & 0.46 & 2.110 & $0.332-13.396$ & 0.43 \\
\hline Others & 0.718 & $0.203-2.533$ & 0.60 & 0.515 & $0.133-1.993$ & 0.34 \\
\hline Marital status & & & 0.19 & & & \\
\hline Single & Ref & & & Ref & & \\
\hline Married & 0.718 & $0.397-1.297$ & 0.27 & 0.634 & $0.285-1.410$ & 0.26 \\
\hline Divorced & 0.862 & $0.331-2.244$ & 0.76 & 0.794 & $0.232-2.712$ & 0.71 \\
\hline Widowed & 0.992 & $0.329-2.988$ & 0.99 & 0.903 & $0.221-3.693$ & 0.89 \\
\hline Cohabiting & 3.125 & $1.016-9.615$ & 0.04 & 2.027 & $0.544-7.550$ & 0.29 \\
\hline Separated & 1.190 & $0.224-6.336$ & 0.84 & 1.592 & $0.254-9.984$ & 0.62 \\
\hline Employment & & & 0.29 & & & \\
\hline Employed & Ref & & & Ref & & \\
\hline Unemployed & 1.469 & $0.726-0.975$ & 0.29 & 1.836 & $0.742-4.542$ & 0.19 \\
\hline Occupation & & & 0.24 & & & \\
\hline None & Ref & & & Ref & & \\
\hline Trading & 0.475 & $0.149-1.513$ & 0.21 & 0.809 & $0.198-2.311$ & 0.77 \\
\hline Farming & 0.557 & $0.167-1.859$ & 0.34 & 0.870 & $0.197-3.845$ & 0.86 \\
\hline Civil/public servant & 0.450 & $0.134-1.512$ & 0.20 & 0.672 & $0.127-3.564$ & 0.64 \\
\hline Hairdresser & 0.282 & $0.047-1.706$ & 0.17 & 0.613 & $0.082-4.595$ & 0.63 \\
\hline Seamstress & 0.369 & $0.060-2.274$ & 0.28 & 0.784 & $0.096-6.420$ & 0.82 \\
\hline Businessperson & 0.424 & $0.085-2.121$ & 0.30 & 0.824 & $0.121-5.606$ & 0.84 \\
\hline Others & 0.997 & $0.320-3.104$ & 1.00 & 1.173 & $0.282-4.870$ & 0.83 \\
\hline Place of residence & & & 0.01 & & & \\
\hline Rural & Ref & & & Ref & & \\
\hline Urban & 0.519 & $0.314-0.856$ & 0.01 & 0.751 & $0.394-1.429$ & 0.38 \\
\hline Religion & & & 0.64 & & & \\
\hline Christianity & Ref & & & Ref & & \\
\hline Islam & 0.824 & $0.371-1.920$ & 0.66 & 0.891 & $0.320-2.485$ & 0.83 \\
\hline
\end{tabular}

level of clients' satisfaction, making copayment, receiving all prescribed drugs, proximity to the health insurance office, and awareness of the mobile phone for the renewal of membership influenced a person's decision not to renew their health insurance membership. For example, those who had a good and very good level of satisfaction in their last hospital visit were 0.149 times $(\mathrm{AOR}=0.149 ; 95 \%$ $\mathrm{CI}=0.035-0.640) \quad$ and 0.290 times $\quad(\mathrm{AOR}=0.107 ; 95 \%$
$\mathrm{CI}=0.107-0.785)$, respectively, less likely not to renew their health insurance membership as compared to those who had a poor experience. In addition, those who made no copayments in their last hospital visit were 0.152 times less likely $(\mathrm{AOR}=0.152 ; 95 \% \mathrm{CI}=0.068-0.344)$ not to renew compared to those who made copayments. Those who did not receive all their drugs were 4 times likely $(\mathrm{AOR}=4.191$; $95 \% \mathrm{CI}=2.027-8.668$ ) not to renew compared to those who 
TABLE 3: Logistics regression of household factors that influence the nonrenewal of health insurance membership.

\begin{tabular}{|c|c|c|c|c|c|c|}
\hline \multirow{2}{*}{ Characteristic } & \multicolumn{3}{|c|}{ Univariate logistic regression } & \multicolumn{3}{|c|}{ Multivariate logistic regression } \\
\hline & Odds ratio & 95\% confidence interval & $P$ value & Odds ratio & $95 \%$ confidence interval & $P$ value \\
\hline Income & & & 0.05 & & & 0.01 \\
\hline Below 500 & Ref & & & Ref & & \\
\hline $500-1000$ & 0.655 & $0.337-1.270$ & 0.21 & 0.216 & $0.075-0.617$ & 0.01 \\
\hline $1001-2000$ & 1.323 & $0.673-2.600$ & 0.42 & 0.085 & $0.019-0.382$ & 0.01 \\
\hline $2001-3000$ & 2.426 & $0.704-8.368$ & 0.16 & 0.197 & $0.027-1.433$ & 0.11 \\
\hline Over 3001 & 3.882 & $0.231-65.303$ & 0.34 & 0.369 & $0.010-13.241$ & 0.58 \\
\hline Expenditure & & & 0.01 & & & \\
\hline Below 100 & Ref & & & Ref & & \\
\hline $100-200$ & 1.150 & $0.235-6.608$ & 0.86 & 1.662 & $0.284-9.721$ & 0.57 \\
\hline $201-500$ & 2.732 & $0.602-12.39$ & 0.19 & 7.344 & $1.094-49.263$ & 0.04 \\
\hline $501-700$ & 2.824 & $0.594-13.424$ & 0.19 & 20.720 & $2.398-179.066$ & 0.01 \\
\hline $701-1000$ & 8.625 & $1.796-41.408$ & 0.01 & 46.278 & $4.686-457.004$ & 0.01 \\
\hline Above 1000 & 5.367 & $1.108-29.003$ & 0.04 & 23.890 & $2.219-257.156$ & 0.01 \\
\hline $\begin{array}{l}\text { Health status } \\
\text { Excellent }\end{array}$ & Ref & & 0.01 & Ref & & \\
\hline Very good & 0.488 & $0.115-2.053$ & 0.33 & 0.852 & $0.189-3.849$ & 0.84 \\
\hline Good & 0.134 & $0.032-0.564$ & 0.01 & 0.266 & $0.057-1.250$ & 0.09 \\
\hline Fair & 0.353 & $0.066-1.873$ & 0.22 & 0.439 & $0.062-3.097$ & 0.42 \\
\hline Poor & 0.500 & $0.0313-7.994$ & 0.63 & 0.222 & $0.006-8.736$ & 0.42 \\
\hline Presence of chronic disease in household & & & 0.07 & & & \\
\hline Yes & Ref & & & Ref & & \\
\hline No & 1.868 & $0.916-3.808$ & 0.09 & 2.073 & $0.852-5.044$ & 0.11 \\
\hline Number of individuals in a household & & & 0.01 & & & \\
\hline $1-3$ & Ref & & & Ref & & \\
\hline $4-6$ & 0.462 & $0.276-0.775$ & 0.01 & 0.625 & $0.258-1.514$ & 0.30 \\
\hline 7 and above & 0.873 & $0.351-2.170$ & 0.77 & 0.796 & $0.140-4.515$ & 0.80 \\
\hline Number of children in a household & & & 0.01 & & & \\
\hline 0 & Ref & & & Ref & & \\
\hline 1 & 0.937 & $0.460-1.910$ & 0.85 & 1.008 & $0.442-2.297$ & 0.97 \\
\hline 2 & 0.318 & $0.156-0.652$ & 0.01 & 0.644 & $0.236-1.758$ & 0.39 \\
\hline 3 & 0.419 & $0.196-0.893$ & 0.02 & 0.782 & $0.250-2.448$ & 0.67 \\
\hline 4 & 0.518 & $0.190-1.140$ & 0.20 & 0.919 & $0.229-3.696$ & 0.91 \\
\hline 5 & 0.806 & $0.152-4.278$ & 0.80 & 0.981 & $0.105-9.199$ & 0.99 \\
\hline 6 & 1.450 & $0.321-6.553$ & 0.63 & 1.156 & $0.097-13.791$ & 0.91 \\
\hline Number of aged in household & & & 0.01 & & & \\
\hline 0 & Ref & & & Ref & & \\
\hline 1 & 0.353 & $0.177-0.704$ & 0.01 & 0.718 & $0.312-1.653$ & 0.44 \\
\hline 2 & 0.239 & $0.111-0.652$ & 0.01 & 0.901 & $0.294-2.760$ & 0.86 \\
\hline 3 and above & 4.234 & $0.691-25.935$ & 0.12 & 9.415 & $0.704-125.87$ & 0.90 \\
\hline Wealth status of household & & & 0.19 & & & \\
\hline Poor & Ref & & & Ref & & \\
\hline Middle class & 0.478 & $0.216-1.059$ & 0.07 & 0.488 & $0.1556-1.533$ & 0.22 \\
\hline Rich & 1.050 & $0.084-12.995$ & 0.97 & 1.146 & $0.039-33.246$ & 0.94 \\
\hline
\end{tabular}

received all their drugs. In addition, those who were not aware of the mobile renewal were 3 times more likely $(\mathrm{AOR}=3.139 ; 95 \% \mathrm{CI}=1.462-6.739)$ not to renew compared to those who were aware.

\section{Discussion}

The results of the study show gender and level of education as sociodemographic factors that influence the renewal of health insurance membership. Females were more likely to renew their insurance compared to their male counterparts. This could be attributed to the fact that females use healthcare services frequently due to reproductive health issues. Another reason could be assigned to the free maternal health policy under the national health insurance. Under this policy, pregnant women are registered with the health insurance without paying for registration and premium; hence, women appear to be renewing their health insurance membership more than men. This finding is consistent with findings from previous studies which reported that females were more likely to have active health insurance compared to males $[11,12]$.

In addition, in this study, there was no association between age and renewal of health insurance membership. This is inconsistent with previous studies that report that those who were older were more likely to renew their health 
TABLE 4: Systematic factors influencing the nonrenewal of health insurance membership.

\begin{tabular}{|c|c|c|}
\hline Characteristic & $\begin{array}{l}\text { Frequency } \\
(n=417)\end{array}$ & Percentage \\
\hline \multicolumn{3}{|c|}{ Distance from health facility } \\
\hline$>1 \mathrm{~km}$ & 136 & 32.61 \\
\hline $1 \mathrm{~km}-5 \mathrm{~km}$ & 253 & 60.67 \\
\hline $6 \mathrm{~km}-10 \mathrm{~km}$ & 11 & 2.64 \\
\hline More than $10 \mathrm{~km}$ & 17 & 4.08 \\
\hline \multicolumn{3}{|l|}{ Nature of road } \\
\hline Excellent & 2 & 0.48 \\
\hline Very good & 63 & 15.11 \\
\hline Good & 348 & 83.45 \\
\hline Poor & 4 & 0.96 \\
\hline \multicolumn{3}{|l|}{ Experience at hospital } \\
\hline Excellent & 1 & 0.24 \\
\hline Very good & 33 & 7.91 \\
\hline Good & 358 & 85.85 \\
\hline Poor & 25 & 6.00 \\
\hline \multicolumn{3}{|l|}{ Made copayment } \\
\hline Yes & 273 & 65.47 \\
\hline No & 144 & 34.53 \\
\hline \multicolumn{3}{|c|}{ Received all drugs prescribed } \\
\hline Yes & 206 & 49.40 \\
\hline No & 211 & 50.60 \\
\hline \multicolumn{3}{|c|}{$\begin{array}{l}\text { Close to the health insurance } \\
\text { office }\end{array}$} \\
\hline$<1 \mathrm{~km}$ & 26 & 6.24 \\
\hline $1 \mathrm{~km}-5 \mathrm{~km}$ & 212 & 50.84 \\
\hline $6 \mathrm{~km}-10 \mathrm{~km}$ & 157 & 37.65 \\
\hline More than $10 \mathrm{~km}$ & 22 & 5.28 \\
\hline \multicolumn{3}{|c|}{ Awareness of mobile renewal } \\
\hline Yes & 284 & 68.11 \\
\hline No & 133 & 31.89 \\
\hline \multicolumn{3}{|c|}{$\begin{array}{l}\text { Knowledge of mobile renewal } \\
\text { code }\end{array}$} \\
\hline Yes & 104 & 24.94 \\
\hline No & 313 & 75.06 \\
\hline
\end{tabular}

insurance membership $[13,14]$. On the other hand, educational level showed a significant relationship between renewing health insurance status and educational attainment. This is in consistence with previous studies which suggest that those with some form of formal education were more likely to renew their health insurance membership [11]. Our study, however, showed that those with MSLC were more likely not to renew their insurance status contrary to a finding by a previous study which reports that there was no significant relationship between education and individual's decision to renew insurance membership [9].

The study showed no significant relationship between ethnicity and health insurance status contrary to a previous study [11]. Marital status also did not show any statistically significant association with the health insurance status. This is similar to a finding by a previous study [15] but inconsistent with other studies $[9,11]$ which suggest that females who are not married are less likely to have active health insurance compared to the married. This study also did not find any statistically significant relationship between employment and the renewal of health insurance membership. This is similar to a finding reported in a previous study [9]. However, findings in our study were not in line with a study which reported that there is an association between employment and the renewal of health insurance membership [12].

Religion did not have an association with the renewal of health insurance membership. This is inconsistent with other studies that show that Christians are more likely to renew their insurance compared to Muslims and people from other religions [11]. The results of the study did not show statistically significant relationship between the place of residence and the health insurance status. This is inconsistent with a study conducted in Kenya [16] as well as in Ghana [11].

Household income was found to influence a person's decision to renew or not to renew their health insurance. Those who earned more were more likely to renew their health insurance compared to those who earned less. This result affirms a previous study conducted in Ethiopia which found that high-income earners are more likely to renew their health insurance than low-income earners [17]. A similar finding is reported in a study carried out in Ghana $[11,14]$. However, a study carried out in the Dormaa Municipality in Ghana reported findings contrary to those in our study [18].

The study shows a statistically significant relationship between household expenditure and renewal of health insurance status. The multivariate analysis indicates that those who spend more have higher odds of not renewing their health insurance. This could be attributed to the fact that they spend their money on other things which they consider to be more important to them than renewing their health insurance. This is contrary to a previous study which reported that household with higher expenditure have a higher likelihood to renew their health insurance [12].

Health system factors found to influence health insurance nonrenewal were the quality of care at the health facility, making copayments, acquiring all drugs prescribed, closeness to the insurance office, and awareness of mobile renewal. The distance to a health facility did not show any statistical significance. This is contrary to previous studies which showed that those who lived far away from a health facility were less likely to subscribe to the health insurance. If the health facility is far from the individuals, it might cause the person to seek other sources of healthcare, thereby deterring the person from renewing the health insurance $[17,19]$.

The quality of care was found to be statistically significant with the health insurance status. The adjusted odds ratio shows that those who felt they had good and very good quality of care were more likely to renew their health insurance status compared to those who had poor quality of care. The quality of care has been identified as a major factor that affects health insurance use $[10,19,20]$.

In this study, it was found that availability of the prescribed drugs influenced people's decision on the renewal of the health insurance status. Those who did not receive all the 
TABLE 5: Logistic regression analysis on systemic factors influencing health insurance renewal.

\begin{tabular}{|c|c|c|c|c|c|c|}
\hline \multirow{2}{*}{ Characteristic } & \multicolumn{3}{|c|}{ Univariate logistic regression } & \multicolumn{3}{|c|}{ Multivariate logistic regression } \\
\hline & Odds ratio & $95 \%$ confidence interval & $P$ value & Odds ratio & $95 \%$ confidence interval & $P$ value \\
\hline Distance from health facility & & & 0.10 & & & 0.01 \\
\hline$>1 \mathrm{~km}$ & Ref & & & Ref & & \\
\hline $1 \mathrm{~km}-5 \mathrm{~km}$ & 1.671 & $0.945-2.956$ & 0.08 & 0.576 & $0.747-3.212$ & 0.24 \\
\hline $6 \mathrm{~km}-10 \mathrm{~km}$ & 2.309 & $0.582-9.484$ & 0.25 & 0.186 & $0.012-2.774$ & 0.22 \\
\hline More than $10 \mathrm{~km}$ & 3.359 & $1.111-10.157$ & 0.03 & 0.340 & $0.021-5.594$ & 0.45 \\
\hline Nature of road & & & 0.01 & & & \\
\hline Poor & Ref & & & Ref & & \\
\hline Very good & 1.725 & $0.169-17.563$ & 0.65 & 3.18 & 0.109-93.19 & 0.50 \\
\hline Good & 0.600 & $0.061-5.870$ & 0.66 & 0.85 & $0.031-23.44$ & 0.92 \\
\hline Satisfaction level & & & 0.01 & & & \\
\hline Poor & Ref & & & Ref & & \\
\hline Very good & 0.148 & $0.045-0.488$ & 0.01 & 0.149 & $0.035-0.640$ & 0.01 \\
\hline Good & 0.136 & $0.058-0.319$ & 0.01 & 0.290 & $0.107-0.785$ & 0.02 \\
\hline Made copayment & & & 0.01 & & & \\
\hline Yes & Ref & & & Ref & & \\
\hline No & 0.356 & $0.196-0.652$ & 0.01 & 0.152 & $0.068-0.344$ & 0.01 \\
\hline Received all drugs prescribed & & & 0.01 & & & \\
\hline Yes & Ref & & & Ref & & \\
\hline No & 2.33 & $1.406-3.885$ & 0.01 & 4.191 & $2.027-8.668$ & 0.01 \\
\hline Closeness to the health insurance office & & & 0.07 & & & \\
\hline$>1 \mathrm{~km}$ & Ref & & & Ref & & \\
\hline $1 \mathrm{~km}-5 \mathrm{~km}$ & 0.831 & $0.293-2.351$ & 0.73 & 0.558 & $0.159-1.958$ & 0.36 \\
\hline $6 \mathrm{~km}-10 \mathrm{~km}$ & 1.118 & $0.392-3.188$ & 0.84 & 2.373 & $0.672-8.379$ & 0.17 \\
\hline More than $10 \mathrm{~km}$ & 2.908 & $0.797-10.601$ & 0.11 & 53.828 & $3.097-937.410$ & 0.01 \\
\hline Awareness of mobile renewal & & & 0.63 & & & \\
\hline Yes & Ref & & & Ref & & \\
\hline No & 1.136 & $0.681-1.894$ & 0.63 & 3.139 & $1.462-6.739$ & 0.01 \\
\hline Knowledge of mobile renewal code & & & 0.01 & & & \\
\hline Yes & Ref & & & Ref & & \\
\hline No & 2.209 & $1.144-4.263$ & 0.02 & 1.458 & $0.675-3.151$ & 0.33 \\
\hline
\end{tabular}

prescribed drugs were 4 times more likely not to renew their health insurance compared to those who received. This affirms a previous study [9].

\section{Conclusion}

The health insurance nonrenewal rate was low and was influenced by sociodemographic, household, and systemic factors. Therefore, the Municipal Health Directorate and the National Health Insurance Authority need to work on these factors to reach the target of $100 \%$ active coverage in the municipality.

\section{Data Availability}

All data generated or analyzed during this study are included within the article.

\section{Ethical Approval}

Ethical clearance was sought from the Kwame Nkrumah University of Science and Technology Ethics Review Committee on Human Research Publication and Ethics.

\section{Consent}

Permission was sought from the Ejisu-Juaben Health Directorate before data collection began. At the community level, participants were asked to read and sign the consent form prior to the interviews. Participants were assured of the confidentiality of their response and their null association with it at present or in the future. In addition, they were assured that their participation would not affect their relations with the NHIS at present or in the future and that refusal to participate would not attract any penalty.

\section{Conflicts of Interest}

The authors declare that they have no conflicts of interest.

\section{Authors' Contributions}

KMA and KAM conceived and initiated the study. KMA designed the study, provided training and guidance for data collection and analysis, and further prepared the original draft of the manuscript. PA-B and DO assisted with supervision, editing, and technical support in all areas of the 
study. PT and JKB assisted with the data collection and monitored the entire team for data collection. The draft manuscript was critically reviewed by PT. All authors made significant contributions to the final work and approved the manuscript for submission. All authors have read and approved the manuscript.

\section{Acknowledgments}

The authors are grateful to Mrs. Josephine A. Ahorsu, the District Director of Health, Ejisu-Juaben Municipality, and all the staff of the directorate for their various contributions throughout the study.

\section{References}

[1] T. Achoki and A. Lesego, "The imperative for systems thinking to promote access to medicines, efficient delivery, and cost-effectiveness when implementing health financing reforms: a qualitative study," International Journal for Equity in Health, vol. 16, no. 1, p. 53, 2017.

[2] C. Zhang, M. S. R. Rahman, M. M. Rahman, A. E. Yawson, and K. Shibuya, "Trends and projections of universal health coverage indicators in Ghana, 1995-2030: a national and subnational study," PloS One, vol. 14, no. 5, Article ID e0209126, 2019.

[3] D. Martin, A. P. Miller, A. Quesnel-Vallée, N. R. Caron, B. Vissandjée, and G. P. Marchildon, "Canada's universal health-care system: achieving its potential," The Lancet, vol. 391, pp. 1718-1735, 2016.

[4] W. Zeng, C. Kim, L. Archer, S. Omarzaman, M. Y. Jabarkhil, and K. Sears, "Assessing the feasibility of introducing health insurance in Afghanistan: a qualitative stakeholder analysis," BMC Health Services Research, vol. 17, no. 1, p. 157, 2017.

[5] A. S. Yazbeck, W. D. Savedoff, W. C. Hsiao et al., "The case against labor-tax-financed social health insurance for lowand low-middle-income countries," Health Affairs, vol. 39, no. 5, pp. 892-897, 2020.

[6] P. A. Dalinjong and A. S. Laar, "The national health insurance scheme: perceptions and experiences of health care providers and clients in two districts of Ghana," Health Economics Review, vol. 2, no. 1, p. 13, 2012.

[7] J. Okoroh, S. Essoun, A. Seddoh et al., "Evaluating the impact of the national health insurance scheme of Ghana on out of pocket expenditures: a systematic review," BMC Health Services Research, vol. 18, no. 1, p. 426, 2018.

[8] R. K. Alhassan, E. Nketiah-Amponsah, and D. Kojo, "A review of the national health insurance scheme in Ghana: what are the sustainability threats and prospects?" PLoS One, vol. 11, no. 11, Article ID e0165151, 2016.

[9] D. Boateng and D. Awunyor-Vitor, "Health insurance in Ghana: evaluation of policy holders' perceptions and factors influencing policy renewal in the Volta region," International Journal for Equity in Health, vol. 12, p. 59, 2013.

[10] A. M. Kotoh, G. C. Aryeetey, and S. Van der Geest, "Factors that influence enrolment and retention in Ghana' national health insurance scheme," International Journal of Health Policy and Management, vol. 7, no. 5, pp. 443-454, 2018.

[11] E. Badu, P. Agyei-Baffour, I. O. Acheampong, M. Preprah Opoku, and K. Addai-Donkor, "Households sociodemographic profile as predictors of health insurance uptake and service utilization: a cross-sectional study in a municipality of
Ghana," Advances in Public Health, vol. 2018, Article ID 7814206, 13 pages, 2018.

[12] E. Nsiah-Boateng, J. Nonvignon, G. C. Aryeetey et al., "Sociodemographic determinants of health insurance enrolment and dropout in urban district of Ghana: a cross-sectional study," Health Economics Review, vol. 9, no. 1, p. 23, 2019.

[13] D. Acharya, B. Devkota, and B. Wagle, "Factors associated to the enrollment in health insurance: an experience from selected districts of Nepal," Asian Social Science, vol. 15, no. 2, 2018.

[14] R. A. Atinga, G. A. Abiiro, and R. B. Kuganab-Lem, "Factors influencing the decision to drop out of health insurance enrolment among urban slum dwellers in Ghana," Tropical Medicine \& International Health, vol. 20, no. 3, pp. 312-321, 2015.

[15] K. R. Pandey, F. Yang, K. A. Cagney, F. Smieliauskas, D. O. Meltzer, and G. W. Ruhnke, "The impact of marital status on health care utilization among medicare beneficiaries," Medicine, vol. 98, no. 12, 2019.

[16] J. K. Kimani, R. Ettarh, C. Warren, and B. Bellows, "Determinants of health insurance ownership among women in Kenya: evidence from the 2008-09 Kenya demographic and health survey," International Journal for Equity in Health, vol. 13, no. 1, p. 27, 2014.

[17] D. D. Atnafu, H. Tilahun, and Y. M. Alemu, "Communitybased health insurance and healthcare service utilisation, North-West, Ethiopia: a comparative, cross-sectional study," BMJ Open, vol. 8, no. 8, Article ID e019613, 2018.

[18] T. Amo, "The national health insurance scheme (NHIS) in the Dormaa municipality, Ghana: why some residents remain uninsured?" Global Journal of Health Science, vol. 6, no. 3, pp. 82-89, 2014.

[19] C. Jehu-Appiah, G. Aryeetey, E. Spaan, T. de Hoop, I. Agyepong, and R. Baltussen, "Equity aspects of the National Health Insurance scheme in Ghana: who is enrolling, who is not and why?" Social Science \& Medicine, vol. 72, no. 2, pp. 157-165, 2011.

[20] A. Kumi-Kyereme and J. Amo-Adjei, "Effects of spatial location and household wealth on health insurance subscription among women in Ghana," BMC Health Services Research, vol. 13 , no. 1 , p. $221,2013$. 